\title{
Bilateral lateral rotation of the kidneys with their hilum facing laterally (outwards) - Rare anatomical variations
}

\author{
Vinu Gopinath', Mookambika RV², Velayudhan Nair ${ }^{3}$, Rema V Nair ${ }^{4}$, Mohandas Rao KG ${ }^{5}$ \\ ${ }^{1}$ Department of Urology, Mookambika Institute of Medical Sciences, Kulasekaram, Tamil Nadu, India, ${ }^{2}$ Department of Nephrology, \\ Mookambika Institute of Medical Sciences, Kulasekaram, Tamil Nadu, India, ${ }^{3}$ Department of Surgery, Mookambika Institute of Medical \\ Sciences, Kulasekaram, Tamil Nadu, India, ${ }^{4}$ Department of Obstetrics and Gynaecology, Mookambika Institute of Medical Sciences, \\ Kulasekaram, Tamil Nadu, India, ${ }^{5}$ Department of Anatomy, Melaka Manipal Medical College, Manipal University, Manipal, 576 104, \\ India
}

\section{A B S TR A C T}

Among the variations of the renal system, abnormalities of structure and position of kidney along with the variations of renal vessels are reported most frequently. However, reports on rotational abnormalities and abnormal positions of renal hilum are scanty. During routine dissection of the posterior abdominal wall, laterally rotated kidneys with laterally facing hila were observed in about 60-year-old male cadaver. On right side, the hilum was more on the anterior surface of the organ and right renal vein was emerging almost from the middle of the anterior surface at the lateral edge of the hilum. However, the hilum of the left kidney was observed along the lateral border of the organ and left renal artery was crossing transversely anterior to the kidney forming a loop to reach the hilum. It was also observed that because of the lateral position of the hilum, the renal vessels and pelvis where passing over the anterior surface of the kidney. Rotational variations and abnormal locations of renal hilum are of importance in surgical procedures like percutaneous nephrectomy. Further clinical and surgical importance of the case is discussed in the paper.

Key Words: Rotation of kidney, Renal artery variations, Renal vein variations, Renal sinus, Lateral border of kidney, Renal pelvis

\section{INTRODUCTION}

Anomalies of kidney form a significant percentage of the anomalies of urinary system. Anomalies of structure and position of the kidneys are encountered most frequently. ${ }^{1}$ Renal agenesis, ectopic kidneys, pelvic kidney, horseshoe kidney and aberrant renal arteries are the some of the commonly reported renal anomalies and embryological basis for these variations also are well established. ${ }^{2}$ However, abnormalities in rotation and reports of laterally facing renal hilum are very rare.

Normally, renal hilum is found along the medial border of the kidney through which the renal vessels and pelvis pass. ${ }^{3}$ We report a case of bilaterally rotated kidneys with their hila facing anteriorly and laterally.
Access this article online Website:

http://nepjol.info/index.php/AJMS DOI: 10.3126/ajms.v6i5.12414

Address for Correspondence:

Dr. Mohandas Rao K. G, Professor and Head, Department of Anatomy Melaka Manipal Medical College, Manipal University,

Manipal- 576 104, India.

E-mail: mohandaskg@gmail.com; Phone: +919844380839.

(c) Copyright AJMS 
the renal vein and renal artery crossing inferomedially over the anterior surface of corresponding kidneys (Figures 1 and 2). In addition, on left side, the anterior wall of the sinus was not distinct; as a result of that, renal sinus was exposed anteriorly revealing some of its contents. Renal pelvis looked abnormally large and elongated instead of its normal conical shape. Series of major calyces were opening to this large elongated renal pelvis at right angles. In addition, the renal pelvis was becoming abruptly narrow to continue as ureter (Figures 2 and 3).

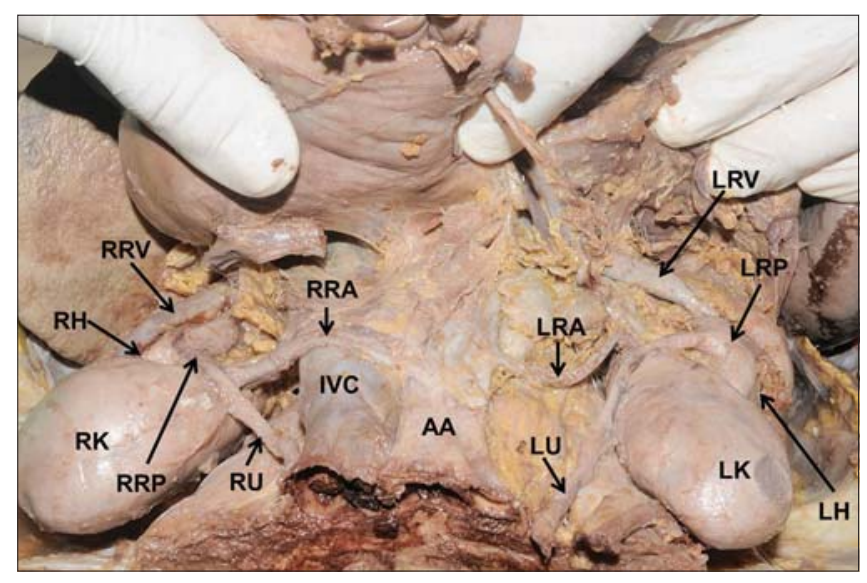

Figure 1: Dissection of the abdomen showing right (RK) and left (LK) kidneys. It can be observed that the hilum of right kidney $(\mathrm{RH})$ is shifted ventrolaterally and the hilum of left kidney $(\mathrm{LH})$ is shifted laterally due to the rotation of the kidneys. It can also be noted that the right renal vein (RRV), right renal pelvis (RRP), left renal vein (LRV) and left renal pelvis (LRP) are crossing the anterior surface of the corresponding kidneys as they emerge from the renal sinus. Right renal artery (RRA) arising from abdominal aorta (AA) crossing anterior to the inferior vena cava (IVC) to reach the renal hilum is also seen. (LRA- left renal artery, $\mathrm{RU}$ - right ureter, LU- left ureter).

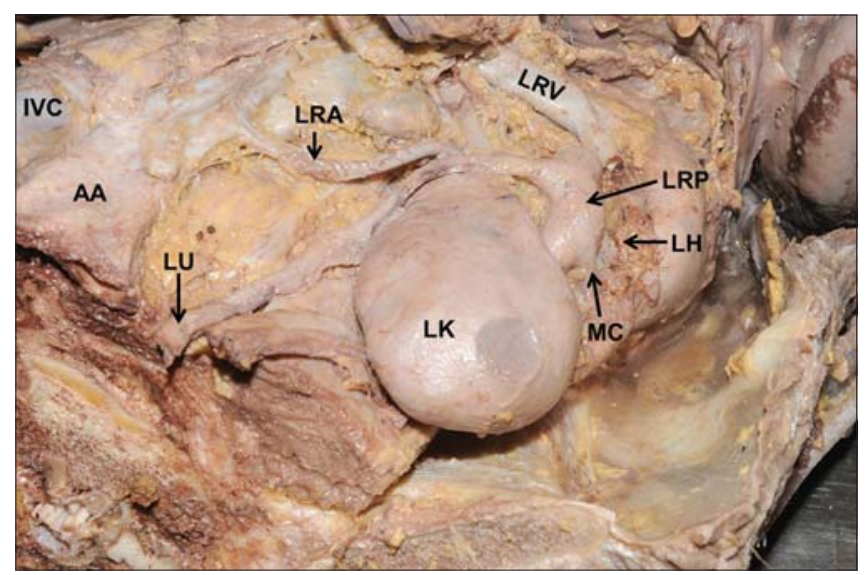

Figure 2: Dissection of the abdomen showing the closer view of left kidney (LK). It can be observed that the kidney is (reverse) rotated about $180^{\circ}$ and hilum (LH) is shifted laterally. It can also be noted that the left renal vein (LRV) and left renal pelvis (LRP) are crossing the anterior surface of the kidney as they emerge from the renal sinus. (LRA- left renal artery, IVC- inferior vena cava, AA- abdominal aorta, LU- left ureter, MC- major calyx).

\section{DISCUSSION}

Rotation of the kidneys facing their hila laterally is considered to be one of the rare variations of the renal system. Das and Amar observed only one case of malrotation out of 27 patients who underwent surgery for ureteropelvic junction obstruction. ${ }^{1}$ Patil et al. have reported a case of bilateral malrotation and lobulation of kidneys, with open hilum exposing the contents of the sinus. ${ }^{4}$ Different types of rotational anomalies have been reported. 1. Nonrotation type; where renal pelvis is found ventral to kidney, 2. Incomplete rotation type; where renal pelvis is found ventromedially, 3. Reverse rotation type; which is a kind of excessive rotation where the position of renal pelvis varies depending upon the degree of kidney rotation. ${ }^{5}$ The case reported here falls more under the $3^{\text {rd }}$ (reverse rotation) type especially on the left side. However, on the right side, degree of rotation is lesser which is closer to $2^{\text {nd }}$ (nonrotation) type. There are reports that the rotational anomalies are often associated with aberrant renal vessels. ${ }^{6-8}$ But, it is interesting to note here that though the renal vessels had abnormally loopy course, there were no aberrant renal arteries in the present case.

There are different theories proposed to explain the embryological basis for the renal rotation. However, most of these theories reported to be speculative. ${ }^{9}$ According to Priman, whether the rotation involves twisting of kidney around its longitudinal axis or is it a case of differential growth of the lateral lip of the hilum is not known. ${ }^{10}$

From surgical point of view, knowledge of possible renal rotational variations is vital especially in interpretation of

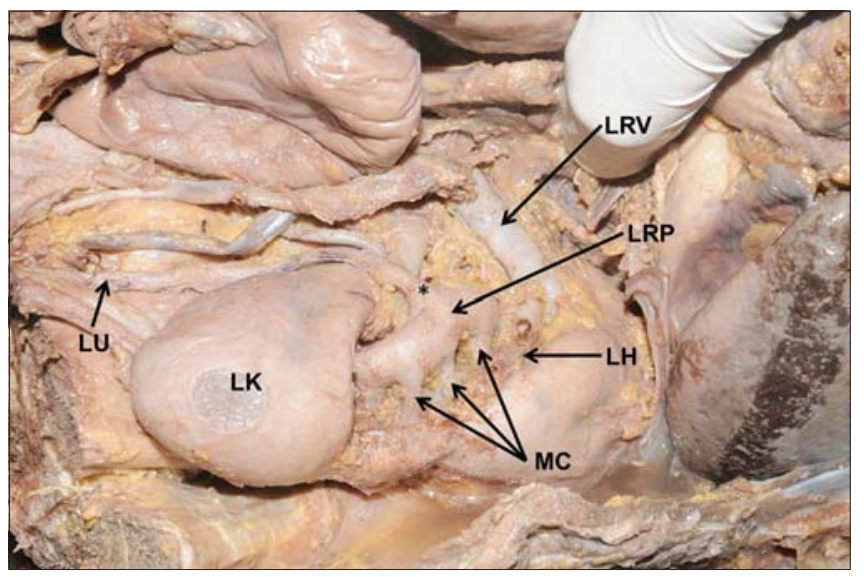

Figure 3: Dissection of the abdomen showing the closer view of left kidney (LK) exposing renal sinus. It can be observed that the major calyces (MC) open to the renal pelvis (LRP) at right angles. Asterisk $\left({ }^{*}\right)$ indicates the abrupt narrowing (constriction) of the left renal pelvis (LRP). (LU- left ureter, LRV- left renal vein, LH- left renal hilum). 
intravenous pyelograms (IVP). A rotated kidney may be attributed for displacement of paravertebral mass. Renal calyces and pelvis may look peculiar in IVP. Deviation in the course of the ureter near the lower pole of the kidney as in the present case may create an impression that there is a mass in the lower pole of kidney. In surgical procedures like percutaneous nephrectomy and preoperative diagnostic evaluation of the kidney donors, knowledge of such rotational anomalies of the kidneys becomes even more significant. ${ }^{11}$ In addition, abrupt narrowing of the pelvis and right angular termination of ranal calyces into renal pelvis as in the present case may cause hydronephrosis especially when neighboring organs like stomach, intestine or pancreas press on it. Abrupt narrowing of the pelvis may constitute potential site of entrapment of renal calculus.

\section{CONCLUSION}

Rotational abnormalities and abnormal positions of renal hilum are rare. We observed bilaterally rotated kidneys with their hila facing anteriorly and laterally on right and left sides respectively. Knowledge of rotational variations and abnormal locations of renal hilum are important in interpretation of IVP and in surgical procedures like percutaneous nephrectomy.

\section{REFERENCES}

1. Das $S$ and Amar A. Ureteropelvic junction obstruction with associated renal anomalies. Journal of Urology, 1984; 131: 872-878.

2. Sadler TW. Langman's medical embryology. Eds. $11^{\text {th }}$ Edition, Wolters Kluwer India Pvt. Ltd, New Delhi. 2010; 235-243.

3. Standring S, Borley NR, Collins P, Crossman AR, Gatzoulis MA, Healy JC, et al. Gray's Anatomy: The Anatomical Basis of Clinical Practice. 40 Edition, Elsevier, Churchill Liwingstone, London. 2008. p. 1225-1238.

4. Patil ST, Meshram MM and Kasote AP. Bilateral malrotation and lobulation of kidney with altered hilar anatomy: a rare congenital variation. Surg Radiol Anat 2011; 33:941-944.

5. Hollinshead WH. Anatomy for Surgeons, in: The kidneys, ureter and suprarenal glands. $2^{\text {nd }}$ Ed.: Harper \& Row publishers, New York, Vol. 2, 1971; p. 518-573.

6. Braash WF. Anomalous renal rotation and associated anomalies. J Urol 1931; 25: 9.

7. Olsson $\mathrm{D}$ and Wholey M. Vascular abnormalities in gross anomalies of kidney. Acta Radiologica 1964; 2:420.

8. Nathan H and llya G. Right and left accessory renal arteries arising from a common trunk associated with unrotated kidneys. J Urol 1984; 132: 7-9.

9. Pollack HM and Mc Clennan BL. Clinical Urography, in: Congenital anomalies of the urinary tract. $2^{\text {nd }} \mathrm{ed}, \mathrm{W}$. B. Saunders Co. Philadelphia, Vol. 1, 2000; p.661-911.

10. Priman J. A consideration of normal and abnormal positions of the hilum of the kidney. Anatomical Record. 1929; 42:355.

11. Ingole IV and Ghosh SK. Laterally Rotated Kidney- A Rare Congenital Anomaly. J. Anat Soc India 2005; 54: 19-21.

Authors Contribution:

Dr. Vinu Gopinath and Dr. Mookambika wrote the case and discussed the clinical aspects of the case, Dr. Reema V Nair and Prof. Velayudhan Nair helped in the preparation of the manuscript and proof reading. and Dr. Mohandas Rao helped in the dissection and review of literature.

Source of Support: Self funding, Conflict of Interest: No conflicts of interest. 